
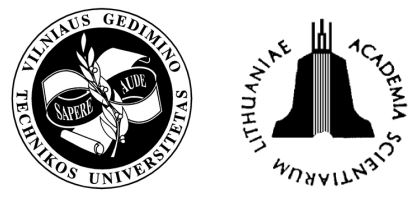

\title{
LINEAR OPTIMIZATION MODEL OF URBAN AREAS' OPERATING EFFICIENCY
}

\author{
Katalin Tanczos ${ }^{1}$, Arpad Torok ${ }^{2}$ \\ Dept of Transport Economics, Budapest University of Technology and Economics \\ H-1111 Bertalan Lajos 2; Budapest, Hungary. Phone +361 4631008; +361 4633287 \\ E-mails: ${ }^{1}$ ktanczos@kgazd.bme.hu, ${ }^{2}$ artorok@kgazd.bme.hu
}

Received 7 January 2007; accepted 2 May 2007

\begin{abstract}
The efficiency of urban transportation is getting more and more important because of the increasing rate of mobility demand. To plan, control and organize urban transportation in the most efficient way, we also need to consider the aspects of land use. To handle both of the mentioned urban planning areas together, we shall develop models, which are able to pay attention to all of their restrictive factors in the most simple way. It is a possible solution to simulate the urban area through a linear programming model.
\end{abstract}

Keywords: Urban transportation, urban planning, transportation policy, linear programming, optimization.

\section{Introduction}

Motto:

"And what, I said, will be the best limit for our rulers to fix when they are considering the size of the State and the amount of territory which they are to include, and beyond which they will not go? What limit would you propose? I would allow the State to increase so far as is consistent with unity; that, I think, is the proper limit" [1].

Nowadays Europe's settlement-structure can be characterized as a strongly urbanized area. Besides this, in the urbanized areas a high level of GDP concentration can be observed. That shall make us care for the operational efficiency of the urban areas more and more studiously. The urban areas' dynamic horizontal and vertical growing continually makes the matter of efficiency more and more important.

To analyze the operational efficiency of an urbanized area, we shall fix some basic properties, which can be valuated and optimized - as a result of the dissection (e. g.: extension, structure or shape of the city).

To effectuate a uniform, consistent methodology for urban planning - taking into consideration the viewpoints of the land use and the transportation according to Socrates' words, we need to approach to the subject considering complex social and economic aspects. To develop a flexible, consistent, and well-handleable model, - based on the existing equilibrium models of urban planning - we shall emphasize the capital advantages of the hereinafter given models.

\section{The prepared methodologies}

In Edwin S. Mills' monocentric city model, exogenously determined amounts of several goods must be exported outside the urban area. These goods are produced in the urban area and are used not only for export but also as input in production of other goods and for final consumption in urban area. Inputs used in the production of each goods include outputs of other goods, various kinds of labor, land and capital. The most important kind of substitution in urban areas is between-land and non-land inputs. The proportions of between-land and non-land inputs determine population and employment densities and building heights. Factor of substitution is represented in this model by a set of input-output coefficients for buildings of various heights. Goods and services are produced in tall buildings by using large capital-output and small landoutput ratios [2]. The model works with linear equations and inequalities, which can be solved - so the model can be optimized - through a linear programming process.

The other type of the analyzed models is the general equilibrium model of polycentric urban area. This model development had two related goals. The first, a technical goal, is to develop and present a fully closed computable general equilibrium model of urban land use without any predetermined employment locations and with endogenous traffic congestion. In this model, the locations of firms and consumers are interdependent and, in equilibrium, firms and consumers are dispersed everywhere within the urban area. The study of such a model is motivated by the fact that the standard 
monocentric model of urban land use assumes that all employment is located in the Central Business District (CBD) and that all travel is to the CBD and is workrelated. This standard model has lost its relevance as the weakening of agglomeration economies continues to cause urban land uses to evolve towards a higher degree of polycentricism and employment dispersion. The paper's second goal is to solve the computable general equilibrium model in order to examine how the imposition of congestion tolls would modify land use patterns in the dispersed urban form. This focus is motivated by the fact that theoretical analyses of the effects of congestion tolls have relied almost exclusively on the standard monocentric model. Hence, the numerous analyses published do not shed light on how the imposition of tolls would change the dispersion of jobs and residences within an urban area [3].

\section{Structure of the model}

The equilibrium model - developed by Alex Anas - has a compact socioeconomic approach, which allows us to take into account the decision process of different social levels.

The most advantageous part of Mills' model is the tractability of its mathematical methodology. The linear optimization seems to be advantageous, by reason of its tractable and flexible characteristics.

The disadvantages shall be obviated but can be described as the analyzed models' deficiency. Mills' monocentric model does not contain all of the economic components, as long as Anas' methodology is too complex to use it in everyday planning works.

The model - which shall be developed - should include the mentioned advantages and avoid the observed disadvantages of the prepared methodologies.

\subsection{The setting}

The activity-based approach to traffic planning allows us to handle the different travel-motivation types separately. Of these activity-travel attributes, the location of participation spatially pegs the daily activity-travel patterns of individuals [4].

It follows that we can define such travelmotivation types, which are relatively irrespective of each other (e. g.: working, entertainment, shopping).

The spatial representation of the urban area shall be taken into a rectangular grid [hence the extension of a square does not depend on the distance of the center, in contrast to the polar frame of reference].

The above-mentioned two assumptions allow us to assay the traffic generating effects spatially and in activity types separately, so the developed model can be easily extended [additional external effects, additional traffic generating activities].

After revealing the basic properties of the model, we shall analyze its components.

\subsection{Firms}

The decision making processes of firms have serious effects on city's spatial structure. The location of the service and production activities denotes a significant rate of the traffic generating effects. That is a serious reason, why we cannot separate the matter of land use and traffic planning. Each firm is intent to maximize their profit, so they want to choose their location to optimize their production process.

Let $\Pi$ be the profit function of the firms, which depends on the volume and the price of the output $\left[X_{j r}, p_{j r}\right]$, the volume and the price of the labor input $\left[\sum_{i} M_{i j r}, \omega_{j r}\right]$, and the volume and the price of the land input $\left[Q_{j r}, \rho_{j r}\right]$ of the firms producing the $r^{\text {th }}$ type of goods in the $j^{\text {th }}$ square, then:

$$
\Pi=\sum_{j=1}^{J}\left(X_{j r} \cdot p_{j r}-\sum_{i} M_{i j r} \cdot \omega_{j}-Q_{j r} \cdot \rho_{j}\right) .
$$

To focus on the connection between transportation and land use, and to avoid nonlinearity, long-term or indirectly respective variables (those variables, which have no direct or short-term effect on transportation or land use), for exogenous $\left[X_{j r}, p_{j r}, \omega_{j r}, q_{j r}\right]$ have been chosen.

To provide the linear characteristic of the model, we have to use linear production function:

$$
X_{r j}=M_{j r} \cdot \sigma_{j}+Q_{j r} \cdot \mu_{j} .
$$

This type of the CES functions can be made more realistic with additional practical restrictive factors:

$$
\begin{aligned}
& M_{j r 0} \leq M_{j r} ; \\
& Q_{j r 0} \leq Q_{j r} .
\end{aligned}
$$

$M_{j r 0}$ and $Q_{j r 0}$ can be defined as the minimum level of the needed source to produce the $r^{\text {th }}$ goods in the $j^{\text {th }}$ square.

\subsection{Consumers}

Consumers take as given all costs [e .g.: transportation, traffic generating activities], procedure times [e. g.: transportation, traffic generating activities], the distribution of employment, and activity locations:

$$
\begin{aligned}
& \sum_{r k m}\left(Z_{i j, r k m} \cdot\left(p_{j r} \cdot+2 \cdot t_{i j, k, m}\right)\right)+\rho_{i} \cdot q_{i j}+ \\
& \sum_{m} 2 \cdot v \cdot t_{i j, k, m}+S_{i j} \cdot\left(T-\sum_{m} T_{i j, m}-L_{i j}\right) \cdot \varpi_{j}= \\
& \left(T-\sum_{m} T_{i j, m}-L_{i j}\right) \cdot \varpi_{j}+\frac{\sum_{i} A_{i} \cdot \rho_{i}}{\sum_{i} N_{i}} .
\end{aligned}
$$

$Z_{i j, r k m}$ is the number of shopping trips made by a worker, employed at $j$, with the transportation mode $m$, purchasing the $r^{\text {th }}$ type of commodity. All shopping and 
working trips are started from home (zone $i$ ). $q_{i j}$ is the lot size of the consumer at home zone $i$, working in the $j^{\text {th }}$ zone. $L_{i j}$ is the leisure time of the analyzed consumer, $\rho_{i}$ is the rent for land at $i$, and $\omega_{j}$ is the hourly wage at $j$. $T$ is the total hours available for work, leisure, and travel per period. $v$ is the work days or one-way commutes per period [year]. $t_{i j, k, m}$ is the money cost of oneway travel from $i$ to $k$, for a consumer working at $j$ [cc: specific constant infrastructure costs, in point of time of return; c.ext : specific external costs]. $T_{i j}$ is the total travel time per period, and $2 \cdot v$ is the number of commutes per period.

$$
\begin{aligned}
& T_{i j, m}=2 \cdot v \cdot g_{i, j, m}+2 \cdot g_{i, k, m} \cdot \sum_{r k m} Z_{i j, r k m} \\
& t_{i j, k, m}=c . c_{i, k, m}+\bar{\sigma}_{j} \cdot g_{i, k, m}+c . \operatorname{ext}_{i, k, m} .
\end{aligned}
$$

$S_{i j}$ is the saving rate of consumers living at $i$, working at $j . g_{i k}$ is the one-way travel time of a shopping trip from home zone $i$ to $k$. Usually we can define the travel time of a transportation mode $\left[g_{i, j, m}\right]$ from the congestion function as a nonlinear equation, where the resistivity of a route depends on the capacity utilization of the route, $T_{0}$ is the travel time in the case of no congestion, $f_{i, j, m}$ is the amount of examined traffic flow, $L p_{i, j, m}$ is the capacity of the examined route, $a$ and $b$ are the examination parameters:

$$
g_{i, j, m}=T_{0} \cdot\left(1+a\left(\frac{f_{i, j, m}}{L p_{i, j, m}}\right)^{b}\right) .
$$

Besides it is possible to adapt the mentioned function to a linear one by bringing in particular restrictive factors:

$$
\begin{aligned}
& g_{i, j, m}=T_{0}+C \cdot \frac{f_{i, j, m}}{L p_{i, j}} \\
& T_{0}, C=f\left(\frac{L p_{i, j}}{f_{i, j, m}}\right) ; \\
& f_{i, j, m}=2 \cdot v \cdot \sum_{r} M_{i j r}+2 \cdot \sum_{r} M_{i j r} \cdot \sum_{r k} Z_{i j, r j m} .
\end{aligned}
$$

Workers are equal owners of all the land in the urban area. Hence, aggregate land rents are redistributed. Let $N_{i}$ be the exogenous number of consumers in the $i^{\text {th }}$ zone and $A_{i}$ the amount of land in zone $i$, then the dividend is:

$$
\frac{\sum_{i}\left(A_{i} \rho_{i}\right)}{N} .
$$

In short-term period [daily] the consumer can choose the mode of transport and the term of leisure hours. The mentioned properties must be described by the chosen endogenous variables $\left[g_{i j, k, m}, L_{i j}, S_{i j}\right]$.

\subsection{Optimization}

The optimization process must contain both of the mentioned socioeconomic interests. The developed function [SE] shall have to take account of firms' and consumers' economic intentions. That is why we propose to contract the two different budget function's [of firms and of consumers] adequate parts. Accordingly we can optimize the social effectiveness of the urban area:

$$
\begin{aligned}
& \max S E=\sum_{i=1}^{I} \sum_{j=1}^{J} \sum_{r=1}^{R}\left(L_{i j}+S_{i j} \cdot\left(T_{j, r}-T_{i j, m}-L_{i j}\right)\right) \times \\
& \omega_{j}-\sum_{j=1}^{J} \sum_{r=1}^{R}\left(M_{j r} \cdot \omega_{j}+Q_{j r} \cdot \rho_{j}\right) .
\end{aligned}
$$

The consumers' interests are included in the first part of the maximization function. $L_{i j}$ leisure time's monetarized value can be compared with $S_{i j}$, the value of savings. So the consumer's leisure and working time ratio - which is seriously affected by the travel time can be optimized.

The firms' interests are contained within the second part of the function. The endogenous variables $\left[M_{j r}, Q_{j r}\right]$ describe the firms' expenditures, which must be minimized. So we have to maximize the offset of the mentioned part of the function.

\section{Conclusions}

The deterioration of urban mobility conditions, which have been threatening the quality of life and the competitiveness of urban areas, has led to the recognizance of the need to strive for sustainability in urban mobility patterns. The integration of land use and transport policies has been frequently pointed out as a potential contribution to more sustainable mobility patterns. Nevertheless, in spite of the broad political and academic recognition for the need to integrate land use and transport policies to foster more sustainable mobility patterns, such integration is seldom put into practice. This can be imputed, in part, to the lack of policy design support tools for policy integration, in contrast to the abundance of tools for comparison of alternative policy strategies. Urban mobility problems, such as traffic congestion, have been threatening the quality of life and the competitiveness of urban areas as well as their sustainable development [5].

In this respect, the European Commission has identified the following two main requirements for mobility management: reduction of travel needs and making remaining travel more sustainable. The integration of land use and transport policies has been recognized as a more effective approach to meeting these requirements [5].

An important advantage of the created model is its artless tractability. To optimize the model, we need 
equally transportation and land use data, so the model is able to value the mentioned aspects together.

We can analyze the effects of different transport policies, with continuous changing of the exogenous variables according to the analyzed transport policy.

Further on, the model can be extended in many ways. The module of externalities can be worked out more in detail, which recently is an indispensable area of urban planning. Another important improving possibility is assaying of freight-transportation [local, transit] in the point of land use. Of course the future development of the model shall also pay attention to the development of the actual mathematical methodology.

\section{References}

1. PLATO. The Republic of Plato. Electronic Text Center, University of Virginia Library. Available from Internet: $<$ http://etext.lib.virginia.edu/toc/modeng/public/PlaRepu.h tml>.

2. MILLS, E. S. Mathematical model for urban planning. Urban and Social Economics in Market and Planned Economies. 1974, Vol 40 (2).

3. ANAS, A.; XU, R. Congestion, Land use, and job dispersion: a general equilibrium model. Journal of Urban Economics, May 1999, Vol 45, Number 3, p. 451-473.

4. SIVAKUMAR, A.; BHAT, C. R. A comprehensive, unified framework for analysing spatial location choice. In European Transport Conference 2005 Proceedings: Activity based modeling (CD-ROM).

5. SILVA, C.; PINHO, P. A methodology to assess the contribution of the land use and transport systems to sustainable urban mobility. In European Transport Conference 2005 Proceedings: Activity based modeling (CD-ROM). 